\title{
The Economics of Organized Crime and Optimal Law Enforcement
}

\author{
Nuno Garoupa* \\ Universitat Pompeu Fabra \\ Stanford Law School \\ Email: garoupa@upf.es
}

December 1997

* Revised version of a paper presented at the 14th annual conference of the European Association of Law and Economics, Barcelona, September 1997. Discussions with Roger Bowles, Antony Dnes, Erling Eide, Hugh Gravelle, and Brian Main were very important. Financial support from FLAD, Lisbon, Portugal is gratefully acknowledged. Comments are welcomed. The usual disclaimer applies. 


\begin{abstract}
This paper extends the optimal law enforcement literature to organized crime. We model the criminal organization as a vertical structure where the principal extracts some rents from the agents through extortion. Depending on the principal's information set, threats may or may not be credible. As long as threats are credible, the principal is able to fully extract rents. In that case, the results obtained by applying standard theory of optimal law enforcement are robust: we argue for a tougher policy. However, when threats are not credible, the principal is not able to fully extract rents and there is violence. Moreover, we show that it is not necessarily true that a tougher law enforcement policy should be chosen when in presence of organized crime.
\end{abstract}

Keywords: Crime, Punishment, Law

JEL: K4 


\section{Introduction}

The economic analysis of crime has its starting point with Becker's (1968) seminal work: individuals rationally decide whether to engage in criminal activities by comparing the expected returns to crime with the returns to legitimate business. Hence, crime is less attractive if the government increases the probability (certainty) and severity of punishment. Alternatively, by increasing market opportunities, one makes crime less attractive. Becker's main thesis is that since imposing a fine is costless, this fine should equal an individual's entire wealth and be complemented by a probability of punishment to optimally deter crime.

Most of the literature on crime has focused on the role of deterrence as pointed out in a recent survey by Garoupa (1997). The discussion has been around alternative characterizations of optimal penalties and enforcement strategies in the context of partial equilibrium where the normative criteria is to minimize a given welfare function that measures the social loss resulting from crime. ${ }^{1}$

This paper extends the optimal law enforcement literature to organized crime. The term 'organized crime' has been used with various meaning by scholars and prosecutors in different countries. Some authors use it to define a set of relations among illegal organizations, while others use it to indicate a group of illegal activities performed by a given set of agents. Fiorentini and Peltzman (1995) summarize the following characteristics of organized crime: (i) economies of scale and exploitation of monopolistic prices on the supply of illegal goods and services, (ii) practice of violence against other legal and illegal business, (iii) criminal hierarchy with internalization of negative externalities and management of portfolio of risky activities, (iv) avoidance of resource dissipation through competitive lobbying and corruption, (v) easier access to markets.

\footnotetext{
${ }^{1}$ See also Ehrlich (1996).
} 
The distinction between the two main roles of the criminal organization - as government and as a firm - is especially fruitful when applied to the analysis of policy-making. In this respect, we have to distinguish between three main areas of deterrence policies against organized crime: first, the traditional deterrence strategies based on investment in investigate activities and in the judicial and penitential systems in order to increase the probability of detection of crimes related to the criminal organizations' activities; second, the deterrence strategies related to the regulatory activities of the government; third, the deterrence policies against money laundering and the investment of illegal profits in legal activities.

Economic analysis of organized crime has stressed welfare comparisons between monopoly and competitive supply of bads as in Buchanan (1973) and Backhaus (1979). In a recent paper, Dick (1995) develops an analytical framework in which transaction costs, rather than monopoly power, primarily determine the activities of organized criminal firms. The paper predicts that organized crime is more successful when there is production cost advantage. Grossman (1995) has developed an alternative analysis: the Mafia is modeled as a competitor to the state in the provision of public services. In this literature, the effect of competition between the Mafia and the state on the allocation of resources and the distribution of income is analyzed. The model implies that, as long as taxation allows, competition between the Mafia and the state increases the provision of public services and, thereby, also increases the net income of the representative producer. Accordingly, the representative producer should support the continued existence of the Mafia. The Mafia exists as an alternative provider of production services to the private sector and competes with the government in terms of tax rates and provision of production services, its existence can have a beneficial effect because it moderates the kleptocratic tendencies of the government.

The current theory of optimal law enforcement might be helpful to discuss law enforcement policy in presence of organized crime. However, as 
we show in the paper, the current theory misses one of the most important characteristics of the market for crime when there is a dominant firm which extracts surplus from smaller criminal firms. A criminal organization has a principal of a vertically integrated structure where agents are individual criminal firms. Following Jennings (1984), Konrad and Skaperdas (1994, 1997), Polo (1995), and Skaperdas and Syropoulos (1995), we consider the principal's necessity to discipline its members by introducing an incentive constraint. Depending on how accurate is the principal's set of information about the market, different policy rules are derived. Moreover, we show that it is not necessarily true that a tougher law enforcement policy should be chosen when in presence of organized crime.

\section{Using the current theory}

In this section, we summarize possible applications of results obtained in the economic theory of criminal law when the market for crime is competitive to the case of a cartelized market.

\section{(1) Wealth}

The starting point is Becker's (1968) theory described before. One corolary of this thesis is that severity of punishment increases with wealth. As a consequence, one could argue that punishment should be more severe in presence of organized crime because members of a Mafia are usually wealthy, or wealthier than petty crooks. This observation can be counter-argued by Polinsky and Shavell (1991) thesis that above a certain level of wealth, all individuals should face the same punishment because that will be enough to optimally deter them given the appropriate probability of detection and punishment.

\section{(2) Externality}

It has been noted in the literature that expected punishment should increase with the harmfulness of the criminal act, as in Polinsky and Shavell 
(1992). One can argue that organized crime is usually associated with more harmful crimes and so law enforcement policy should be tougher.

\section{(3) Risk neutrality}

As in the Arrow-Lind Theorem, we can say that when criminals are organized, they behave as risk neutral individuals even though they may be risk averse individually. From Polinsky and Shavell (1979), we know that the maximal fine result does not apply when individuals are risk averse. As a consequence, in presence of organized crime, a harsher policy should be enforced because individuals behave as if they were risk neutral.

\section{(4) Avoiding detection}

Bebchuk and Kaplow (1993) have shown that punishment should be tougher on those who are more able at avoiding detection and punishment. It is popular noted, as in Robinson (1994), that criminal organizations are much better at avoiding detection than individual crooks. That author cites the US Department of Justice saying 'the crooks keep so far ahead of us, we will never completely close the net'. This is a fourth argument for a tougher policy when in presence of organized crime.

\section{(5) Corruption}

It has been shown in the literature that corruption weakens criminal deterrence. As pointed out by Becker and Stigler (1974) and Bowles and Garoupa (1997), in presence of corruption, the government must design different law enforcement policies, including being tougher on criminal offenses or punishing harshly corruption. It is much easier for a criminal organization to engage on corruption than individuals because of economies of scale and access to information. Thus, in presence of organized crime, not only criminal punishment, but detection and punishment of corruption should be tougher.

\section{(6) Incapacitation and jail sentences}

Most of the optimal law enforcement literature considers the benefits and costs of criminal deterrence. Alternatively, we can consider criminal 
incapacitation as in Shavell (1987). Those criminals who have higher probability of committing a criminal act again should face tougher jail sentences to free society from them. In other words, more dangerous criminals should face a more severe punishment to incapacitate them from repeating offenses. As noted by Robinson (1994), criminal organizations welcome the most dangerous criminals in the world: 'today's criminals make the Capone crowd and the old Mafia look like small time crooks'. Therefore, members of criminal organizations should face a more severe punishment because they signal their higher likelihood of repeating offenses.

These observations do not recognize the structural and institutional problems faced by a criminal organization. These problems emerge because a criminal organization is a vertical structure where there are information problems and incentives to extract rents. Konrad and Skaperdas (1997) consider the issue of credible threats and incentive effects within a gang. They show that there is a reputation problem and emphasize the role of strategic up-front investment. As long as threats are credible, contracts in the criminal world are self-enforced.

In this paper, we model the criminal organization as a vertical structure where the principal extracts some rents from the agents through extortion. Depending on the principal's information set, threats may or may not be credible. As long as threats are credible, the principal is able to fully extract rents. In that case, the results obtained by applying standard theory of optimal law enforcement are robust: we argue for a tougher policy. However, when threats are not credible, the principal is not able to fully extract rents and there is destruction in the market. As a consequence, it might be optimal to choose a less harsher law enforcement policy depending on the social cost of this destruction and violence.

An alternative way of looking at this result is to say that as long as transaction costs are irrelevant in the criminal world, law enforcement policy should be harsh. However, if transaction costs are high and have a social 
value, law enforcement policy should be designed taking them into account.

The paper goes as follows: in section 3, we discuss the basic model; in section 4, we introduce a criminal organization where the principal has accurate information; in section 5 , we allow for imperfect information. The main conclusions are pointed out in section 6 .

\section{Model with a competitive criminal market}

\section{Small firms}

We start by considering an economy where risk-neutral homogenous individuals can work in two different sectors: legal sector and illegal sector. As in Muller and Opp (1986) and Grossman (1991), each individual has to allocate his working time $l$ within these two sectors. The number of hours spent in the illegal sector is $n l$. Accordingly, the number of hours spent in the legal sector is $(1-n) l$.

The working time $l$ is private information of individuals. The government does not observe each individual's working time. Differences on working time represent different preferences for leisure. These preferences are private information. The government knows that the working time $l$ is distributed across the population according to a distribution $q(l)$ with support $[0, L]$.

The legal sector pays $w$ per hour. The illegal sector pays $z(n l)$ per $n l$ hours, where $z^{\prime}>0$ and $z^{\prime \prime}<0$. The payoff function $z($.$) exhibits decreasing$ returns to scale. In this economy, working in the illegal sector is punished with probability $p$. The punishment for working in the illegal sector is $f z(n l)$, where $f \leq 1$.

Each individual maximizes expected income:

$$
V=w(1-n) l+(1-p f) z(n l)
$$


Table 1: Comparative static analysis

\begin{tabular}{c|cccc}
\hline & $l$ & $p$ & $f$ & $w$ \\
\hline$n^{*}$ & - & - & - & - \\
\hline $1-n^{*}$ & + & + & + & + \\
\hline$V^{*}$ & + & - & - & + \\
\hline
\end{tabular}

and the first-order condition is:

$$
V_{n}=(1-p f) z^{\prime} l-w l=0
$$

and the second-order condition is always satisfied:

$$
V_{n n}=(1-p f) z^{\prime \prime} l^{2}<0
$$

Solving this optimization problem, the optimal share of time spent in the illegal sector is $n^{*}(l, p f, w)$. Comparative static results are shown in Table 1.

\section{The optimal policy}

Unlike the choice of $n^{*}$ by individuals and the choice of $f$ by the courts, the choice of $p$ is a public choice made by the government. This variable is chosen to maximize a social objective function. We consider the usual utilitarian social welfare function ${ }^{2}$ :

$$
\begin{aligned}
W & =\int_{0}^{L}\left\{V^{*}-(h-p f) z\left(n^{*} l\right)\right\} q(l) d l-x(p) \\
& =\int_{0}^{L}\left\{w\left(1-n^{*}\right) l+(1-h) z\left(n^{*} l\right)\right\} q(l) d l-x(p)
\end{aligned}
$$

where $h$ is the harm induced by spending time in the illegal sector and $x(p)$ is the cost function of law enforcement where $x^{\prime}>0$ and $x^{\prime \prime}>0$. The budget of

\footnotetext{
${ }^{2}$ Following Usher (1986), we can further consider other social welfare objective functions. One is what Usher (1986) calls a 'democratic objective', where gains from illegal activities are not included in the social objective. A third objective function is what Usher (1986) calls the 'Leviathan objective' where the government maximizes its own budget, without any concern for social welfare.
} 
this law enforcement agency is funded by lump-sum taxation. The first-order condition is:

$$
W_{p}=\int_{0}^{L}(p f-h) z^{\prime} \ln _{p}^{*} q(l) d l-x^{\prime}=0
$$

and we assume that $W$ is strictly concave in $p$ in the nonnegative orthant so that the second-order condition is always satisfied.

Solving this optimization problem gives us the optimal law enforcement policy when the market for crime is perfectly competitive.

\section{Model with organized crime and perfect discrimination}

Let us now assume that in this economy there is a criminal organization which profits are provided by extortion of small competitive criminal firms. This criminal organization asks each individual in the market to pay $y$ as a license to work in the illegal sector. As an enforcement mechanism, this criminal organization destroys the business of those who do not join the organization with probability $r$. The resources to produce $r$ are invested upfront. The principal cannot be detected and punished, only each individual can be detected and punished.

Each individual joining this criminal organization keeps his own business and pays a fixed rent $y$. If an individual prefers a solo career, he faces a probability $r$ of being destroyed by this organization. Let us assume that the organization is able to discriminate individuals in terms of working time: the extracted rent $y$ can be conditional on $l$. As a consequence, the organization extracts all surplus by asking $r V^{*}$ which is the maximum amount individuals are willing to pay. This criminal organization chooses $r$ to maximize expected profits. The organization's per-capita expected profits are:

$$
\Pi=r \int_{0}^{L} V^{*} q(l) d l-C(r)
$$


where $C(r)$ is the cost of producing the probability $r$ of destroying solo careers, such that $C^{\prime}>0$ and $C^{\prime \prime}>0$. The first-order condition of this problem is:

$$
\Pi_{r}=\int_{0}^{L} V^{*} q(l) d l-C^{\prime}=0
$$

and the second-order is always satisfied. The optimal probability $r^{*}$ decreases with $p$. The reason is that a tougher law enforcement policy implies that each small firm has less to contribute to the organization: the rent must decrease and, by consequence, the probability of destroying independent business should decrease.

\section{Optimal policy}

The social welfare from a social utilitarian point of view must take into account the criminal organization's expected profits. The social welfare functional to be maximized is now:

$$
\bar{W}=W-C\left(r^{*}\right)
$$

We have shown that in this case $r^{*}$ decreases with the probability $p$. Accordingly, this introduces an extra marginal gain in the first-order conditions. When a criminal organization exists and is able to discriminate individuals, the law enforcement policy should be tougher. The only role of a principal with perfect information is to extract surplus from small firms with a transaction cost. Destruction of business does not actually occur because all criminals pay the rent. This transaction cost happens in the criminal world, between small crooks and a big criminal organisation. A social utilitarian government worries about it and uses the probability of punishment $p$ to control it. 


\section{Model with organized crime and imper- fect discrimination}

Suppose now that the organization cannot discriminate individuals: the rent $y$ cannot be conditional on $l$. The organization must ask the same rent to each small firm. An individual joins the organization if and only if :

$$
V^{*}-y \geq(1-r) V^{*} \Rightarrow l \geq k(y, r, p, f)
$$

An individual joins the organization if and only if his preferences for leisure are such that his working time is greater than $k$. To show this result, recall from Table 1 that $V_{l}^{*}$ is positive. Those individuals who work more are willing to pay the rent. Those individuals who work less have less to lose and so they are not willing to pay the rent (see figure 1). Accordingly, the critical value $k$ increases with the fixed rent $y$ and with the probability of detection $p$, and decreases with the probability $r$. The organization's expected profits are:

$$
\Pi=y(1-Q(k))-C(r)
$$

and the first-order conditions of this problem are:

$$
\begin{gathered}
\Pi_{r}=-y q(k) k_{r}-C^{\prime}=0 \\
\Pi_{y}=-y q(k) k_{y}+(1-Q(k))=0
\end{gathered}
$$

and the second-order conditions are assumed to be satisfied.

The optimal probability of destruction $r^{*}(p, f)$ and the optimal rent $y^{*}(p, f)$ are related by the rule that equals the ratio of marginal benefits to the ratio of marginal costs:

$$
-k_{r} / k_{y}=C^{\prime} /(1-Q(k))
$$


In general, the comparative static results are ambiguous. Suppose the government follows a tougher law enforcement policy. Each small firm earns less, and so the number of individuals willing to pay a rent decreases, ceteris paribus. As in the case of perfect information, one could argue that the organization should decrease the rent, and by consequence the probability of destroying independent business should decrease. When the organization has perfect information such rule guarantees that individuals will keep paying a rent. The only consequence is that the organization extracts a smaller surplus. When the organization has imperfect information, some individuals do not pay rent. The decision of paying rent depends on $l$ which is private information and on $y / r$. Accordingly, to increase the number of individuals paying rent one should decrease $y / r$ which implies that $r$ should increase, ceteris paribus. This is the source of ambiguity in the comparative static results.

In summary, the effect of the policy instruments in the probability $r$ is ambiguous because there are two opposite arguments: (i) the probability $r$ should go down when there is a tougher policy because the fixed rent goes down, and so it is relatively more costly to enforce this arrangement because the extracted surplus is smaller; (ii) the probability $r$ should go up when there is a tougher policy because more individuals prefer not to pay rent, and so the enforcement of this arrangement needs to be tougher.

\section{Optimal policy}

In this case, some individuals do not pay a rent and face the possibility of having their business destroyed by this organization. The social utilitarian functional welfare is now:

$$
\bar{W}=W-C\left(r^{*}\right)-r^{*} \int_{0}^{k} V^{*} q(l) d l
$$

It is no longer true that a tougher policy should be enforced when a organization with imperfect information exists. Two reasons for that: (i) it is 
no longer true that the probability $r^{*}$ necessarily decreases with the policy instruments; (ii) the number of individuals willing to pay a rent decreases with the policy instruments, ceteris paribus. As a consequence, a tougher policy leads to more individuals having their business destroyed, ceteris paribus.

When there is imperfect information, the transaction cost is larger because some business is actually destroyed. Furthermore, it is no longer clear if this transaction cost decreases with the policy instruments.

\section{Conclusion}

We have modeled a criminal organization as a vertical structure where the principal extracts some rents from the agents through extortion.

The main result of this paper is that it may be optimal to choose a less tough law enforcement policy when there is organized crime. This result is derived from the observation that vertical integration in the criminal world is enforced by destroying the business of those who do not comply with the norms. A tougher policy may induce more destruction: in a sense there is competition between the government and the criminal organization to decide who is tougher, who is more frightful. As a consequence, the loss in welfare can be large.

\section{References}

1. Backhaus, J., 1979, Defending organized crime? A note, Journal of Legal Studies, vol. 8, pages 623-631.

2. Bebchuk, L. A., and Kaplow, L., 1993, Optimal sanctions and differences in individual's likelihood of avoiding detection, International Review of Law and Economics, vol. 13, pages 217-224. 
3. Becker, G., 1968, Crime and punishment: an economic analysis, Journal of Political Economy, vol. 76, pages 169-217.

4. Becker, G., and Stigler, G. J., 1974, Law enforcement, malfeasance and compensation of enforcers, Journal of Legal Studies, vol. 3, pages 1-18.

5. Bowles, R. and Garoupa, N., 1997, Casual police corruption and the economics of crime, International Review of Law and Economics, vol. 17 , pages $75-87$.

6. Buchanan, J. M., 1973, A defense of organized crime?, in The Economics of Crime and Punishment, edited by S. Rottenberg. American Enterprise Institute.

7. Dick, A. R., 1995, When does organized crime pay? A transaction cost analysis, International Review of Law and Economics, vol. 15, pages 25-45.

8. Ehrlich, I., 1996, 1996, Crime, punishment and the market for offenses, Journal of Economic Perspectives, vol. 10, pages 43-67.

9. Fiorentini, G. and Peltzman, S., 1995, Introduction, in The Economics of Organised Crime, edited by G. Fiorentini and S. Peltzman, Cambridge University Press and CEPR.

10. Garoupa, N., 1997, The theory of optimal law enforcement, Journal of Economic Surveys, vol. 11, pages 267-295.

11. Grossman, H. I., 1991, A general equilibrium model of insurrections, American Economic Review, vol. 81, pages 912-921.

12. Grossman, H. I., 1995, Rival kleptocrats: the mafia versus the state, in The Economics of Organised Crime, edited by G. Fiorentini and S. Peltzman, Cambridge University Press and CEPR. 
13. Konrad, K. A. and Skaperdas, S., 1994, Extortion, University of California mimeo.

14. Konrad, K. A. and Skaperdas, S., 1997, Credible threats in extortion, Journal of Economic Behavior and Organization, vol. 33, pages 23-39.

15. Jennings, W. P., 1984, A note on the economics of organized crime, Eastern Economic Journal, vol. 3, pages 315-321.

16. Muller, E. N. and Opp, K. D., 1986, Rational choice and rebellious collective action, American Political Science Review, vol. 80, pages 471-487.

17. Polinsky, A. M. and Shavell, S., 1979, The optimal trade-off between the probability and magnitude of fines, American Economic Review, vol. 69 , pages $880-891$.

18. Polinsky, A. M. and Shavell, S., 1991, A note on optimal fines when wealth varies among individuals, American Economic Review, vol. 81, pages 618-621.

19. Polinsky, A. M. and Shavell, S., 1992, Enforcement costs and the optimal magnitude and probability of fines, Journal of Law and Economics, vol. 35, pages 133-148.

20. Polo, M., 1995, Internal cohesion and competition among criminal organisations, in The Economics of Organised Crime, edited by G. Fiorentini and S. Peltzman, Cambridge University Press and CEPR.

21. Robinson, J., 1994, The laundrymen: inside the world's third largest business, Pocket Books: London.

22. Shavell, S., 1987, A model of optimal incapacitation, American Economic Review, vol. 77 (AEA Papers and Proceedings), pages 107-110. 
23. Skaperdas, S., and Syropoulos, C., 1995, Gangs as primitive states, in The Economics of Organised Crime, edited by G. Fiorentini and S. Peltzman, Cambridge University Press and CEPR.

24. Usher, D., 1986, Police, punishment, and public goods, Public Finance, vol. 41, pages $96-115$. 